\title{
Editorial: Early Avian Evolution
}

\author{
Jingmai Kathleen O'Connor ${ }^{1,2 *}$, Daniel J. Field ${ }^{3,4}$ and Corwin Sullivan ${ }^{5,6}$ \\ ${ }^{1}$ Field Museum of Natural History, Chicago, IL, United States, ${ }^{2}$ Institute of Vertebrate Paleontology and Paleoanthropology, \\ Chinese Academy of Sciences, Beijing, China, ${ }^{3}$ Department of Earth Sciences, University of Cambridge, Cambridge, \\ United Kingdom, ${ }^{4}$ Museum of Zoology, University of Cambridge, Cambridge, United Kingdom, ${ }^{5}$ Department of Biological \\ Sciences, University of Alberta, Edmonton, AB, Canada, ${ }^{6}$ Philip J. Currie Dinosaur Museum, Wembley, AB, Canada
}

Keywords: Aves, stem birds, paleornithology, evolution, avian flight

\section{Editorial on the Research Topic}

\section{Early Avian Evolution}

The study of early avian evolution-how birds evolved from dinosaurs and radiated into the most diverse group of amniotes on the planet-is one of the most dynamic areas of research in paleontology, fueled not only by the rapid rate of discovery of new specimens (see Foth et al.; Musser and Clarke; and Xing et al.) and sheer volume of available material (see Zheng et al.) but also by the innovative application of new analytical methods to key evolutionary questions (see Heers et al.; Liu et al.). Also critical to our understanding is the exceptional level of preservation of many Mesozoic and early Cenozoic bird fossils, which not uncommonly preserve soft tissues and other indicators that may provide key insights into the biology of these organisms (see articles by Clark and O'Connor; Foth et al.; Xing et al.; Zheng et al.). In putting together this research topic, our aim was to further expand our understanding of early avian evolution by gathering a body of work highlighting the diversity of research currently being undertaken in this area. As such, articles published in this topic have augmented our understanding of a variety of important areas related to early avian evolution, including the recognition of new taxonomic diversity (see Clark and O'Connor and Musser and Clarke), insights into the evolution of key avian traits such as flight (Heers et al.) and a toothless beak (see Louchart et al. and Zheng et al.), and the piecemeal evolution of crown avian biology (see Atterholt et al. and Heers et al.).

Fossil specimens examined in this research topic come from Lagerstätten around the world, sampling strata that range in age from Early Cretaceous to early Eocene and thus capture over 70 million years of avian evolutionary change. The contributing researchers are globally distributed, hailing from Argentina, Canada, China, France, Germany, Switzerland, the United Kingdom and the United States. Lead authors represent the complete spectrum of career stages, from Master's and $\mathrm{PhD}$ students to well-established scientists. This speaks to the importance of multiple forms of diversity in science and perhaps especially in paleontology, in which we rely on a comprehensive view of the global fossil record in order to understand broad evolutionary questions. The immense benefit of bringing together young minds from diverse backgrounds clearly shines throughout the entirety of this research topic.

Two articles in this research topic address the origins of the unique, rapid development that characterizes modern birds. Atterholt et al. use histology to document a previously unrecognized level of developmental complexity in Late Cretaceous enantiornithines, and Foth et al. describe the first known Early Cretaceous ornithuromorph representing an early ontogenetic stage, revealing in the process a primitive pattern of development comparable to that observed in other basal, nonneornithine avian lineages and non-avian dinosaurs. While the vast majority of living birds grow to adult size rapidly, well within the first year of growth and in some cases within mere weeks (Lovette and Fitzpatrick, 2004), non-neornithine birds grew slowly, fledging well before skeletal maturity in a manner similar to non-volant theropods (Chinsamy et al., 2020). Accordingly, ontigimorphs may have occupied distinct ecological niches at different ontogenetic stages. Although it seems clear that 


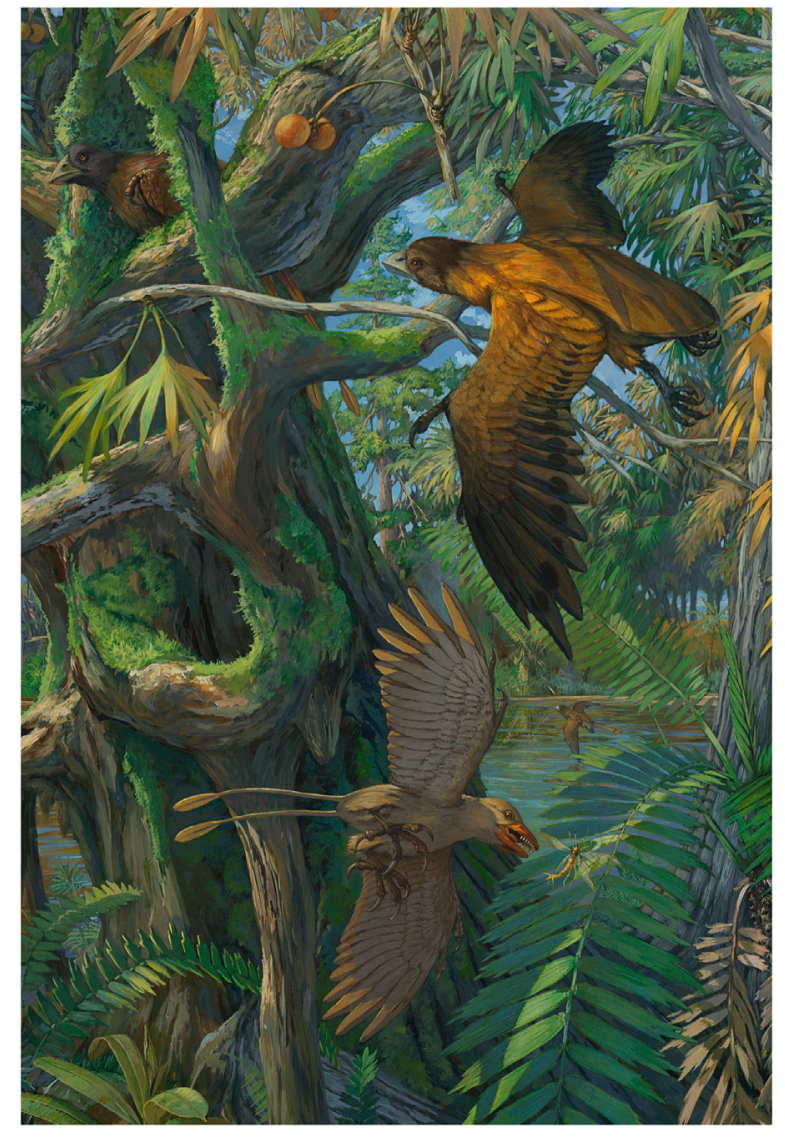

FIGURE 1 | Illustration of the Early Cretaceous Jehol avifauna depicting Confuciusornis (Wu et al. and Zheng et al.) together with a bohaiornithid enantiornithine (Liu et al.). Artwork by Michael Rothman.

enantiornithines achieved locomotor independence and sexual maturity prior to skeletal maturity, the histology of Mirarce described by Atterholt et al. reveals startling variation in enantiornithine growth strategies in the Late Cretaceous, also strongly highlighting the necessity of sampling multiple elements in histological studies in order to more accurately capture growth patterns.

In their description of two new Confuciusornis (Figure 1) specimens with rarely preserved traces of the keratinous rhamphotheca, Zheng et al. observe features suggesting that independent origins of a toothless beak in non-neornithines yielded distinctive morphologies contrasting with those found in extant birds. Similarly, Bell et al. document clear differences in hind limb proportions between ornithuromorph and non-ornithuromorph birds. These studies add to the rapidly accumulating evidence that non-neornithine birds were very different from those alive today.

Two new taxa are erected in this research topic. Clark and O'Connor name Fortipesavis prehendens, a probable enantiornithine preserved in $100 \mathrm{Ma}$ Burmese amber, and Musser and Clarke name Nahmavis grandei from the $\sim 50 \mathrm{Ma}$ old Green River Formation. Both taxa are incomplete, limiting interpretations, yet still shed light on important events in avian evolution. Clark and O'Connor's ecological insights into the ethology of unusual Burmese enantiornithines, arising from careful comparisons with extant analogues, suggest that enantiornithines adapted to specific niches on the basis of unique anatomical traits different from those seen in crown birds, possibly due to developmental limitations imposed by their precocial development. Xing et al. report on a new, unnamed specimen, also preserved in Burmese amber, that increases the diversity of this mid-Cretaceous avifauna with regard to both skeletal proportions and plumage patterns. Musser and Clarke observe that Nahmavis, despite potentially being the first Green River charadriiform, also exhibits characteristics of gruiforms, rendering its phylogenetic position uncertain. Such early diverging neornithines are critical for understanding the early diversification of extant avian clades.

In our call for articles we noted that despite the enormous wealth of new data bearing on avian evolution that continues to accrue, numerous controversies exist and major gaps in our understanding remain. In this research topic two lingering controversies are addressed: Liu et al. tackle the purported ingestion of gastroliths for digestive purposes by at least some enantiornithines (Li et al., 2014; O'Connor, 2019), and Louchart et al. investigate the purported retention of teeth in some early Cenozoic crown birds (Lambrecht, 1930). In both cases, numerous analytical methods justify rejection of the original hypotheses, suggesting that bohaiornithid enantiornithines did not ingest gastroliths, and that putative tooth alveoli in young gastornithids are in fact the openings of large vascular canals-supporting the apparent irreversibility of transitions to toothlessness among total-group birds. In addition, the work of Heers et al. speaks to controversies surrounding flight capabilities in basal avian lineages (Olson and Feduccia, 1979; Gatesy and Dial, 1996), strongly supporting the interpretation that despite their relatively plesiomorphic anatomy, basal birds likely achieved about the same level of flight capability as anatomically derived crownward birds (ornithurines) through compensatory features such as the proportionately large deltopectoral crest present in Confuciusornis, Sapeornis, Jeholornis, and enantiornithines. While Novas et al. provide an in-depth look at the morphology of the scapulocoracoid complex, Heers et al. point out the necessity of whole system research for understanding locomotor behaviors as complex as dinosaurian flight.

Even as long-standing controversies are resolved, others continue to arise, as in the case of the unusual pattern of fusion observed by Wu et al. in the basal pygostylian Confuciusornis. In exploring the transition early in avian evolution from a fused scapulocoracoid complex to an unfused scapula and coracoid, Wu et al. detect a strange pattern in Confuciusornis, and more questions are raised than are answered. Similarly, although the purported gastroliths in Bohaiornis are shown by Liu et al. to be something other than ingested stones, the precise nature of these traces remains uncertain and Bell et al. find that phylogenetic influences on skeletal proportions can overshadow ecological ones, complicating morphometrically-based ecological inferences. These articles strongly indicate the need for continuing research as we ask increasingly complex questions about avian evolution and dig deeper using new methods. Together, the collection of articles published in this research topic exemplifies the exciting diversity of research currently being conducted on the early evolution of birds. 


\section{AUTHOR CONTRIBUTIONS}

All authors listed have made a substantial, direct, and intellectual contribution to the work and approved it for publication.

\section{REFERENCES}

Chinsamy, A., Marugán-Lobón, J., Serrano, F. J., and Chiappe, L. M. (2020). Osteology and Life History of the Basal Pygostylian Confuciusornis Sanctus. Anatomical Record 303, 949-962.

Gatesy, S. M., and Dial, K. P. (1996). From Frond to Fan: Archaeopteryx and the Evolution of Short-Tailed Birds. Evolution 50 (5), 2037-2048. doi:10.2307/2410761

Lambrecht, K. (1930). Studien über fossile Riesenvögel. Institutum Regni Hungariae Geologicum 7, 1-37. doi:10.1159/000397953

Li, Z., Zhou, Z., Wang, M., and Clarke, J. A. (2014). A New Specimen of LargeBodied Basal Enantiornithine Bohaiornis from the Early Cretaceous of China and the Inference of Feeding Ecology in Mesozoic Birds. J. Paleontol. 88 (1), 99-108. doi:10.1666/13-052

Lovette, I. J., and Fitzpatrick, J. W. (2004). The Handbook of Bird Biology. New Jersey: Princeton University Press.

\section{ACKNOWLEDGMENTS}

We are grateful to our contributors who have conducted exceptional work truly making this a special topic.

O'Connor, J. K. (2019). The Trophic Habits of Early Birds. Palaeogeogr. Palaeoclimatol. Palaeoecol. 513, 178-195. doi:10.1016/j.palaeo.2018.03.006

Olson, S. L., and Feduccia, A. (1979). Flight Capability and the Pectoral Girdle of Archaeopteryx. Nature 278, 247-248. doi:10.1038/278247a0

Conflict of Interest: The authors declare that the research was conducted in the absence of any commercial or financial relationships that could be construed as a potential conflict of interest.

Copyright (c) 2021 O'Connor, Field and Sullivan. This is an open-access article distributed under the terms of the Creative Commons Attribution License (CC BY). The use, distribution or reproduction in other forums is permitted, provided the original author(s) and the copyright owner(s) are credited and that the original publication in this journal is cited, in accordance with accepted academic practice. No use, distribution or reproduction is permitted which does not comply with these terms. 